\title{
Prediction of crack depth and fatigue life of an Acrylonitrile Butadiene Styrene cantilever beam using dynamic response
}

\author{
Behzad Ahmed Zai ${ }^{1}$, Muhammad A. Khan ${ }^{2}$, Sohaib Z. Khan ${ }^{3}$, Muhammad Asif ${ }^{4}$, Kamran A. Khan ${ }^{5}$, Ahmed N. Saquib ${ }^{6}$, \\ Asif Mansoor ${ }^{7}$, Majid Shahzad ${ }^{8}$, Ahmed Mujtaba ${ }^{9}$ \\ ${ }^{I}$ Department of Engineering Sciences, PN Engineering College, National University of Sciences and Technology \\ (NUST), Islamabad, Pakistan, behzad_zai@pnec.nust.edu.pk \\ ${ }^{2}$ School of Aerospace, Transport and Manufacturing, Cranfield University, UK, muhammad.a.khan@cranfield.ac.uk \\ ${ }^{3}$ Mechanical Engineering Dept. Islamic University of Madinah, KSA, szkhan@iu.edu.sa \\ ${ }^{4}$ Department of Mechanical Engineering, Auckland University of Technology, New Zealand, masif@aut.ac.nz \\ ${ }^{5}$ Aerospace Engineering Dept. Khalifa University, Abu Dhabi, UAE, kamran.khan@ku.ac.ae \\ ${ }^{6}$ Mechanical Engineering Dept. Islamic University of Madinah, KSA, ahmads@iu.edu.sa \\ ${ }^{7}$ Department of Engineering Sciences, PN Engineering College, National University of Sciences and Technology \\ (NUST), Islamabad, Pakistan, asifmansure@gmail.com \\ ${ }^{8}$ Advanced material research division, SUPARCO, Pakistan, dr_majid@engineer.com \\ ${ }^{9}$ Department of Engineering Sciences, PN Engineering College, National University of Sciences and Technology \\ (NUST), Islamabad, Pakistan, ahmed65mujtaba@gmail.com
}

In this paper, a methodology is proposed which can be used to predict the crack growth and fatigue life of a cantilever beam made of Acrylonitrile Butadiene Styrene (ABS) manufactured with fused deposition modeling Three beam configurations based on length $(\mathrm{L}=110 \mathrm{~mm}, \mathrm{~L}=130 \mathrm{~mm}$, and $\mathrm{L}=150 \mathrm{~mm}$ ) are considered. Empirical relationships are formulated between the natural frequency and the crack growth. The analytical and experimental results are found in good agreement for all configurations. Using the experimental data, global relation is formulated for the crack depth prediction. This global relation is useful for an in-situ crack depth prediction with an error of less than10\%. Later a residual fatigue life of these specimens is compared with metallic structure (Aluminum 1050) of similar configuration available in the literature. It is found out that the ABS material has more residual fatigue life compared to the metallic structure at the same frequency drop. Based on remaining fatigue life, ABS material can be a potential material to manufacture machine components under cyclic loads.

Keywords: Fused deposition modeling, dynamic response, crack growth, natural frequency, residual fatigue life

\section{Introduction}

Ever growing product requirements of the consumers have compelled the industries to find an inexpensive and quick solution to cater to their needs. This has led to modern technologies like rapid prototyping (RP) for part fabrication. Ability to develop complex Computer Aided Design (CAD) models with minimum human intervention has revolutionized the market's approach to product fabrication [1]. Therefore, fused deposition modeling (FDM) process has gained popularity amongst the RP techniques in recent time. It is an extrusion-based process that provides a physical form to a designed model via layer-by-layer deposition of the heated plastic filament [2-3]. Acrylonitrile Butadiene Styrene (ABS) material is the most common plastic filament. ABS has revolutionized the industry by providing excellent impact strength, toughness and heat resistance [4]. Moreover, qualities like appearance diversity, lightweight and cost-effectiveness make it more useful for industrial usage [5-6].

FDM was initially introduced as a mean for rapid prototyping. Now it is prominently being used for manufacturing functional components. Advantages like the ease of operation, inexpensive tooling and the flexibility of producing quick and cost-effective durable parts have escalated its use to manufacture functional components in industries such as automotive, agriculture, medical and aerospace [7-8]. FDM is useful for making patterns, molds, mandrels and even tools such as trim and drill [9]. This clear increase of usage in the modern industry stresses the need to investigate the mechanical properties of the parts produced by FDM. This will ensure that they adequately meet in-service loading and operational requirements, thus, can be an effective alternative to traditionally manufactured products. Extensive studies have been conducted which focus on the static properties and the effect of varying the FDM build parameters on these properties. Omer and Bhowmik [10] experimentally examined the time-dependent properties of ABS material by varying the process parameters. Other researchers, Garg et al. [11], Rodriguez et al. [12] and Arivazhagan et al. [13] discussed the anisotropic

Published by ASTM. This is the Author Accepted Manuscript issued with: Creative Commons Attribution Non-Commercial License (CC:BY:NC 4.0). The final published version (version of record) is available online at DOI: 10.1520/JTE20180674. Please refer to any applicable publisher terms of use. 
behavior of the material by varying raster width, angle, orientation, layer thickness and build temperature's effect on the mechanical properties.

Most of the research investigates the static mechanical properties, and there has been little focus on FDM material under cyclic loads. The fatigue characteristics of FDM material are very important especially for cyclic load and vibration bearing components [14]. Zhang et al. [15] explored fatigue, creep and tensile properties of printed ABS materials. More experiments on FDM specimens have been performed to determine their fatigue behavior [16-17]. They found that the process parameter variation has a significant effect on the part reliability of fatigue failure. Zwick [18] successfully determined the effect of orientation on fatigue life. A systematic approach was designed by Ziemian [19] to find the accumulated damage caused by repetitive loading and comparing it with the model predictions within a reasonable error agreement. Fang et al. [20] used scanning electron microscopes (SEM) to observe fatigue crack propagation behavior of ABS alloys. Relationships between crack length, fatigue cycles, crack growth rate and strength intensity factor range was also observed. Fischer and Schöppner [21] experimentally determined the fatigue behavior of the FDM material using UTS machines in different build orientations.

Fatigue failure is caused because of the formation of subsurface damages that initiates a crack when a material is exposed to repetitive loading. Fatigue failure is the most common type of mechanical failure. Being highly unpredictable, it has resulted in many disastrous accidents thus, compelling the researchers to find a solution to predict the crack growth rate and estimate the remaining fatigue life. It can be fairly concluded from the literature that a crack influences the natural frequency, stiffness, amplitude, strain energy and mode shapes of the material [22-24].

Khan et. al. [25] presented the changes in the dynamic behavior because of a crack, i.e., the natural frequency, the stiffness of the beam and the dynamic stability. They have also studied crack initiation and propagation with numerical and experimental approaches. The relation in between the relative length (i.e., crack distance from the fixed end with respect to the length of the specimen) to the depth ratio (i.e., crack depth with respect to the thickness of the specimen) was discussed in detail [26-29]. Tommy J. George's [30] presented a method using a base exited plate resonating at high frequency. The experiment resulted in producing successful cyclic fatigue under variable amplitude loading. Many other researchers adopted a common method using Eigen frequency in determining the depth and location of the crack [31-34].

Khalkar \& Ramachandran [35-38] studied the dynamic behavior of a cracked beam. They covered many aspects including the effect of crack geometry and crack location on dynamic behavior. They also studied the implementation of available mathematical models on various crack geometries. Their research is an excellent contribution to existing literature related to damage quantification. Many other researchers studied the potential for energy absorption in ABS material [3941].

Literature has shown various methodologies in finding the effects of crack propagation and fatigue life. However, there is still a room in devising a novel technique that can show the crack propagation and conclusively estimate the life of the material. Past research has emphasized the dynamic responses of the structure. However, instant values of the dynamic response of a structure are still difficult to use in the analysis and prediction of the crack growth. This paper investigates the interdependencies of the structure's modal behavior, its dynamic response and crack growth in a quantitative manner based on analytical formulation, experimental data, and empirical relations. For validation experimentation, predicted crack growth is compared with the actual observations. A comparative study is also presented to estimate the fatigue life of ABS and a metallic cantilever beam. The obtained results show the possibility to diagnose the crack growth and fatigue life for FDM manufactured beams within the operational conditions.

\section{Experimental procedure}

\subsection{Geometry and manufacturing}

Figure 1 shows the dimensions of the particular shaped cantilever beam. Similar dimensions were used in our previous study for metallic beams [42]. The mounting mechanism of the specimen on shaker is via a shaft as shown in the experimental setup. A $5 \mathrm{~mm}$ hole is required at the fixed end to mount the specimen on a shaker. Maximum bending moment/stress will occur at this end; therefore, a crack can initiate from this hole if $18 \mathrm{~mm}$ width is considered throughout the specimen. To avoid the possibility of crack initiation from fixing location, the specimen was designed to have more ineffective width $(30 \mathrm{~mm})$ and a fillet at the interface of ineffective and effective width. This will ensure to achieve maximum stress concentration in the vicinity of the crack. Consequently, the crack will propagate from the point of concern. 
In order to avoid wrapping during additive manufacture (3D Printing), the thickness of the specimen is set to $5 \mathrm{~mm}$. Three different configurations with the length of $110 \mathrm{~mm}, 130 \mathrm{~mm}$ and $150 \mathrm{~mm}$ are selected to produce different fundamental frequencies. Three different samples of the same length are used to reduce experimental errors.

The specimens are manufactured by fused deposition molding (FDM). In FDM printers, the melted thermoplastic is deposited in layer-by-layer format to create 3D objects. After the deposition of the first layer (one $2 \mathrm{D}$ cross-section along build direction of the 3D object), the build platform of the printer moves downwards by a distance equal to layer thickness to allow deposition of the subsequent layer. This process is repeated until the printing of the 3D object is completed [25 \& 43]. A 3D Systems CubePro Trio is used to manufacture the specimens. All the parameters set in CubePro to manufacture the specimens are summarized in table 1. Figure 2 shows all the major steps to manufacture the specimens. Multiple specimens of the same length are printed by placing them in reverse orientation, which resulted in the auto raster angle of $45^{\circ}$. The standard procedure is applied for manufacturing, which includes applying 3D Systems Cube glue on the platform and placing the platform in water overnight to remove specimens stick on the printer platform. Later, the sidewalks are removed manually as shown in figure 2 .

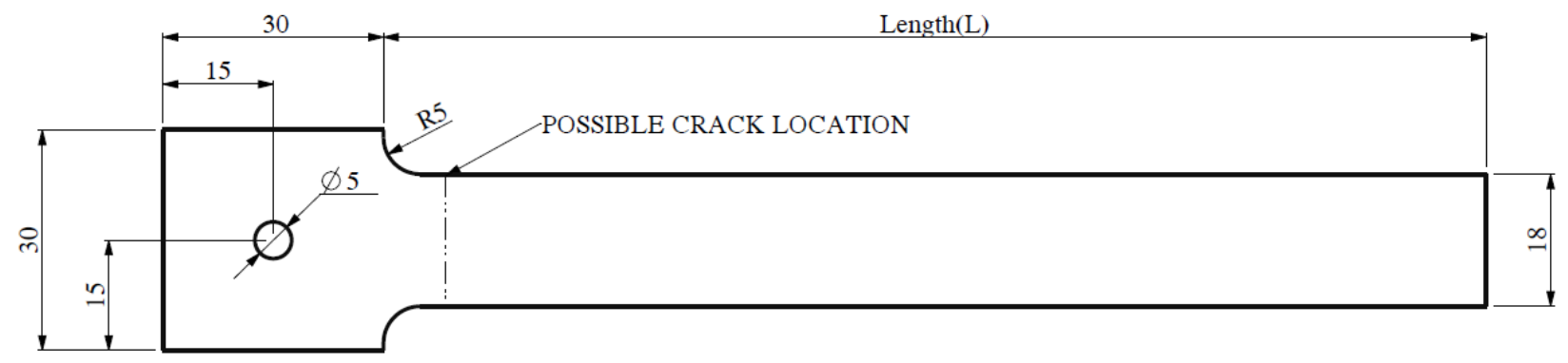

Figure 1: A schematic diagram of a cracked cantilever beam
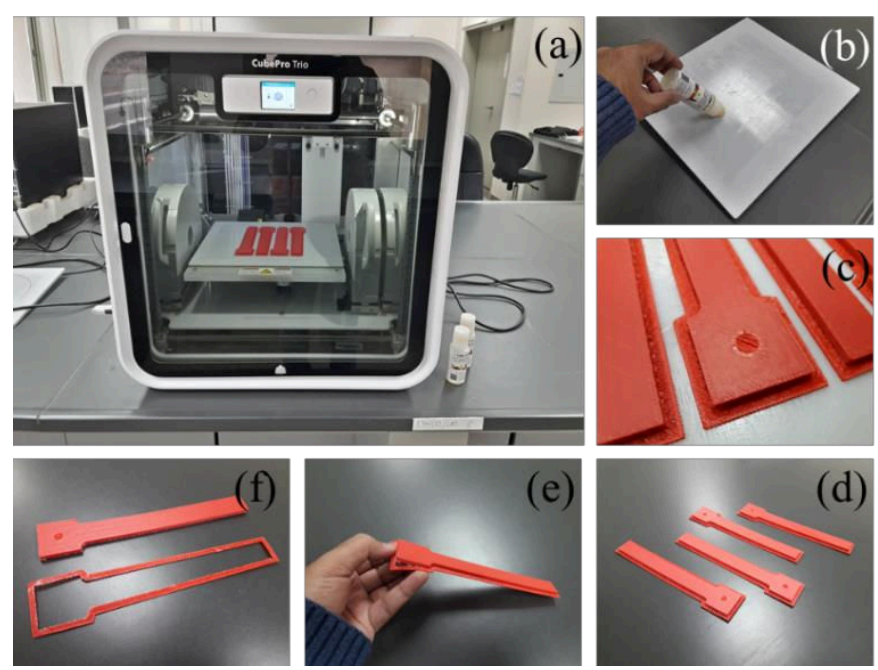

Figure 2: (a) CubePro Printer (b) applying glue on the platform (c) close view of the printed specimens (d) specimens after removal from the platform (e) removal of sidewalk and (f) ready specimen

Table 1: Parameters set in CubePro for manufacturing the specimens.

\begin{tabular}{|c|c|}
\hline Parameter & Value \\
\hline Layer resolution & $200 \mathrm{um}$ \\
\hline Print strength & Solid \\
\hline Pattern & Cross \\
\hline Fill spacing & $1 \mathrm{~mm}$ \\
\hline Top surface layer & 3 \\
\hline Bottom surface later & 3 \\
\hline Outer wall & 1 \\
\hline
\end{tabular}




\begin{tabular}{|c|c|}
\hline Support borders & Disable \\
\hline Sidewalk distance & $4 \mathrm{~mm}$ \\
\hline Sidewalk layers & 2 \\
\hline Sidewalk offset & $0.25 \mathrm{~mm}$ \\
\hline Sidewalk perforation & Yes \\
\hline Sidewalk material & ABS \\
\hline Draw fine features & Disable \\
\hline Nozzle diameter & $0.4 \mathrm{~mm}$ \\
\hline
\end{tabular}

A rectangular open-edged seeded crack is induced in each specimen to initialize crack propagation. This crack is not included in the CAD model for 3D printing to avoid complexities. A jig is designed to apply a precise crack/notch on multiple specimens using a conventional hacksaw as shown in figure 3. The jig is fabricated using mild steel having dimensions conforming to the dimensions of the specimen. A slot in the jig is made to control the hacksaw motion while applying the notch. These slots are made using electric arc cutting method to ensure the dimensional accuracy during notch formation.

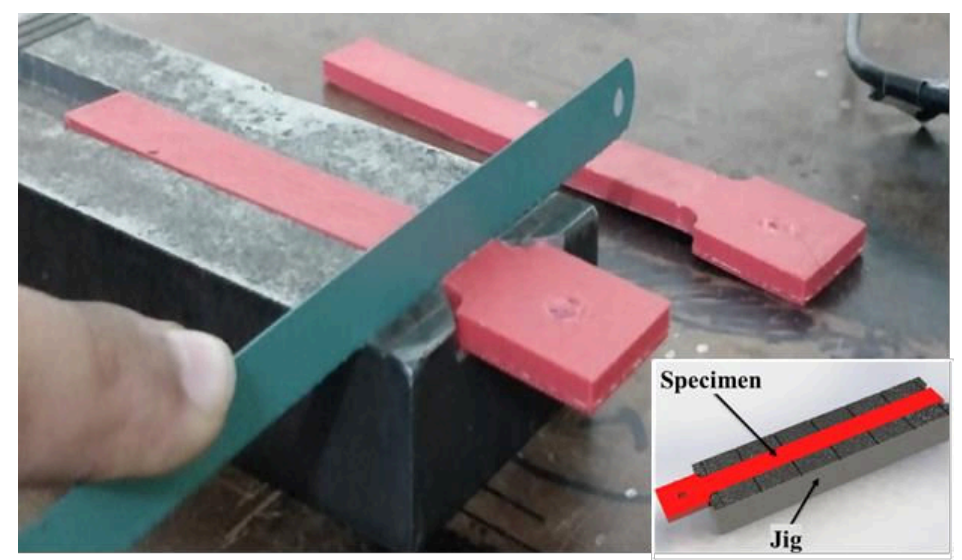

Figure 3: Notch formation on ABS specimen fixed in the jig. Inset is showing 3D CAD model of the jig.

\subsection{Experimental Setup}

The experimental setup consists of a power amplifier (modal LA-200), a signal generator (TENLEE 9200), a data acquisition card (NI-9174) and a modal exciter (MS-100) as shown in figure 4. Time domain measurements are obtained on National Instrument ${ }^{\circ}$ Signal Express. The analysis modules of 'Power Spectrum' and 'Amplitude and Levels' are selected in the Signal Express to identify the frequency response and amplitude value respectively.

Specimens with same pre-selected crack depth are mounted on a modal exciter in a fixed-free condition. An accelerometer is attached at the fixed end on the modal exciter to measure the dynamic response. The exciter and the specimen are firmly attached so that any measured value can provide a cumulative response of the whole system which is largely dominated by the specimen displacement at the free end due to resonance. This amplitude is continuously monitored on Signal Express 'Power Spectrum Module' with a data sampling rate of $25.4 \mathrm{kHz}$. Each experiment is started with a fresh specimen. The signal generator is used to provide a constant peak to peak value of 5 volts in a sine waveform, which consequently provides a constant displacement loading of $\pm 5 \mathrm{~mm}$ to the specimen using power amplifier. 


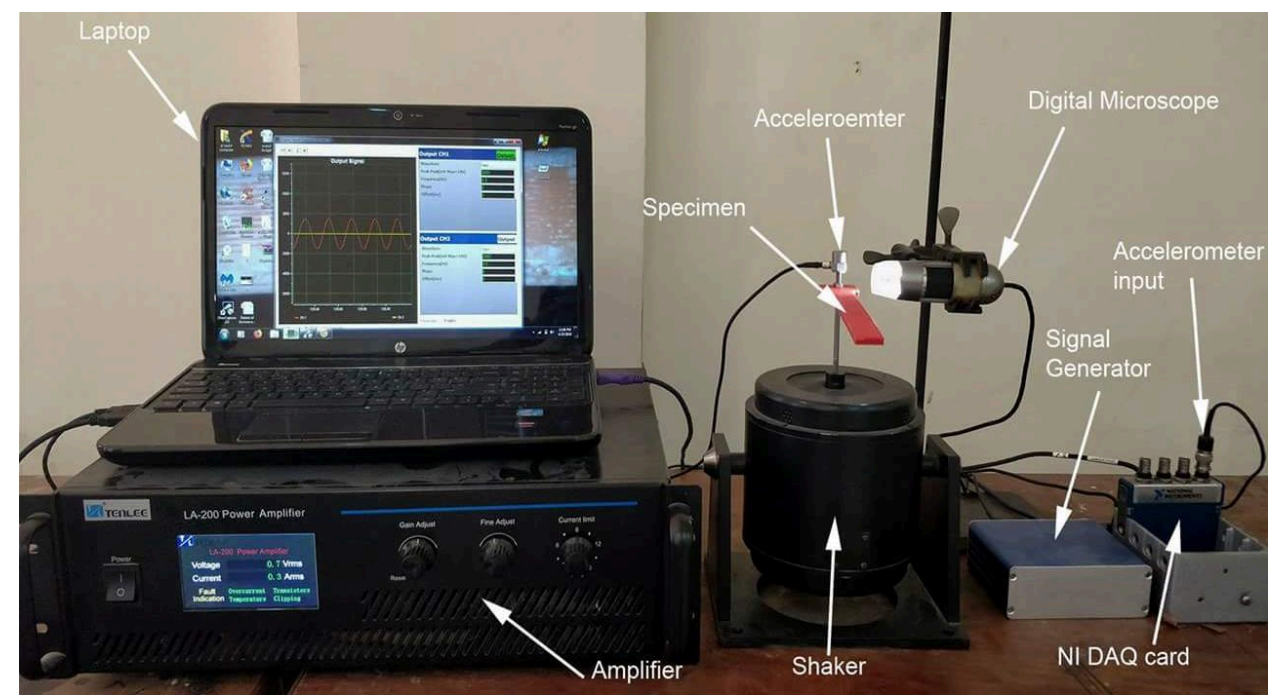

Figure 4: Complete experimental setup with ABS specimen

\section{Analytical formulation between the natural frequency and the crack depth}

Structures demonstrate oscillatory response if an external excitation force interacts with them [24]. The characteristic of this response in terms of amplitude and frequency is dependent on the stiffness of the structure. This stiffness is a direct measurement of the elastic properties of the structural material [44].

In this section, analytical modeling is presented which describes the effect of crack depth in terms of stiffness reduction of a model spring and its possible effect on the overall dynamic response of the structure. Consider the cantilever beam as shown in figure 5. The crack is modeled as massless torsional spring with stiffness $k_{t}$ as shown in equation (1). The relationship between the natural frequencies and crack depth is obtained using the Rayleigh quotient and the governing equations are solved using Newton Raphson method [44].

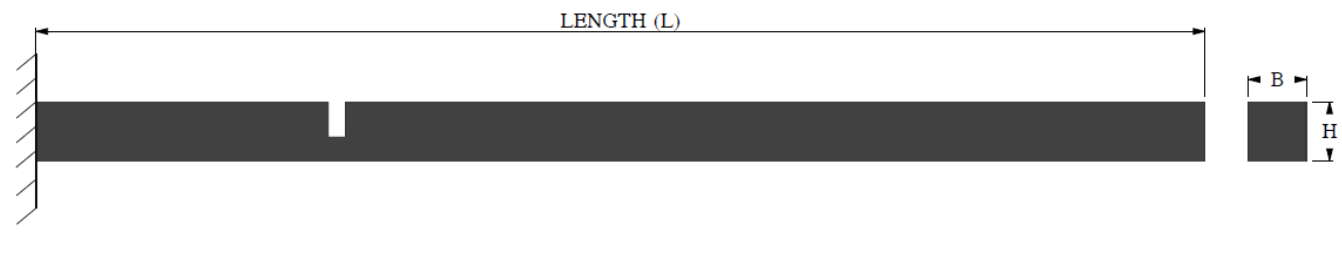

TORSIONAL SPRING

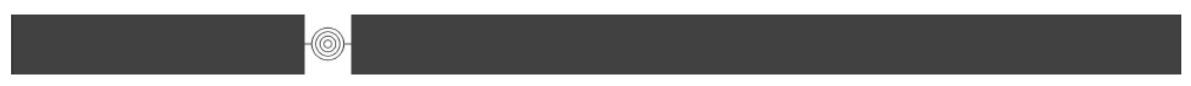

Figure 5: Cantilever beam with crack analyzed as massless rotational spring.

$$
\begin{gathered}
k_{t}=\frac{E B H^{2}}{72 \pi F\left(\frac{t_{c}}{H}\right)} \\
F\left(\frac{t_{c}}{H}\right)=0.638\left(\frac{t_{c}}{H}\right)^{2}-1.035\left(\frac{t_{c}}{H}\right)^{3}+3.720\left(\frac{t_{c}}{H}\right)^{4}-5.177\left(\frac{t_{c}}{H}\right)^{5}+7.553\left(\frac{t_{c}}{H}\right)^{6}-7.332\left(\frac{t_{c}}{H}\right)^{7}+2.491\left(\frac{t_{c}}{H}\right)^{8}
\end{gathered}
$$

Where:

$B=$ width of the beam

$H=$ height of the beam

$t_{c}=$ crack depth

$E=$ modulus of elasticity

$F\left(\frac{t_{c}}{H}\right)=$ crack function.

Free bending vibration of a beam is identified by well-known differential equation as shown in equation (3). Applying boundary conditions $y(0)=0,\left.y^{\prime}\right|_{@ x=0}=0$ and $\left.y^{\prime \prime}\right|_{@ x=L}=0$ to find mode shape and bending moment as shown in equation (4) - (6), 


$$
\begin{aligned}
& E I \frac{\partial^{4} y}{\partial x^{4}}+\rho A \frac{\partial^{2} y}{\partial t^{2}}=0 \\
& y(x)=y_{0}\left[1-\cos \left(\frac{\pi x}{2 L}\right)\right] \\
& y^{\prime}=y_{0}\left(\frac{\pi}{2 L}\right)\left[\sin \left(\frac{\pi x}{2 L}\right)\right] \\
& y^{\prime \prime}=y_{0}\left(\frac{\pi}{2 L}\right)^{2}\left[\cos \left(\frac{\pi x}{2 L}\right)\right]
\end{aligned}
$$

Where:

$\rho=$ density of the beam material

$I=$ moment of inertia

$x=$ longitudinal location of the crack on the beam from fixed end

$y_{0}=$ initially assumed displacement of mode shape.

The curvature of the beam is the second derivative of the beam deflection; therefore, the bending moment can be derived from beam curvature and flexural rigidity (EI) as shown in equation (7). The total strain energy can be derived from direct strain and strain energy due to bending as shown in equations (8) - (9). Reduction in strain energy and change in natural frequency due to crack can be found out using equations (10) - (12), presented by Majid et. $\mathrm{Al}$ [45].

$$
\begin{aligned}
& M=E I y^{\prime \prime} \\
& u=\frac{E I}{2} \int_{0}^{L}\left(y^{\prime \prime}\right)^{2} d x \\
& u=\frac{E I}{64} \pi^{4}\left[\frac{1}{L^{3}}\right]\left(y_{o}\right)^{2} \\
& \Delta u=\frac{M^{2}}{2 k_{t}} \\
& \Delta \omega_{n c}=\frac{\Delta u}{2 u} \omega_{n} \\
& \omega_{n c}=\omega_{n}-\Delta \omega_{n c}
\end{aligned}
$$

Where:

$M=$ bending moment

$u=$ strain energy

$\Delta \mathrm{u}=$ change in strain energy

$\omega_{n c}=$ natural frequency of a cracked beam

$\Delta \omega_{n c}=$ difference between the natural frequencies of the uncracked and cracked beam.

Equation (12) can be used to analytically calculate the natural frequencies of the cracked beam for various crack depths. These equations can be merged to be written in a generalized form as shown in equation (13). It is a proposed modified equation which summarizes all the variables used in the referred models. It can be noted that the natural frequency of cracked beam is independent of the initially assumed value of mode shape and material properties. However, it depends on the natural frequency of the uncracked beam (or at the previous crack depth), crack location and geometrical parameters of the specimen.

$$
\omega_{n c}=\left[1-\left\{\frac{72 \pi I F\left(\frac{t_{c}}{H}\right)}{B H^{2} L}\left(\cos \left\langle\frac{\pi x}{2 L}\right\rangle\right)^{2}\right\}\right] \omega_{n}
$$




\section{Results and discussion}

\section{1 \\ Crack depth prediction and its validation}

The proposed methodology consists of an empirical relationship between the crack depth, length, and the natural frequency of the selected beam. A significant number of experiments are required to form an empirical relation. This empirical relation is expected to predict the crack depth using natural frequency and length of the specimen. A criterion known as percentage replication (PR) is commonly used to define the percentage of reliability of the results based on experimental results as shown in equation (14) [46].

$$
P R=100\left[1-\frac{L_{p}}{n}\right]
$$

Where:

$L_{p}=$ number of varying parameters

$n=$ total number of experiments

In this work total three lengths are considered and for each length, three specimens are tested. This will make the reliability of the data set of $67 \%$. It suggests that the predicted results based on these empirical correlations will have an accuracy of $67 \%$. In the start of each experiment, three fresh specimens of each length with pre-defined crack depth are mounted one by one on the test rig and the accelerometer was installed at the top of the modal exciter knob. The setup was capable of analyzing and recording the in-situ dynamic response of the specimen while vibrating at any frequency. An impact test is carried out to determine the fundamental frequency of a fresh specimen experimentally.

The specimen is set to run at an operating frequency using the signal generator. Initially, this operating frequency is equal to the fundamental frequency obtained from the impact test. Simultaneously, the root mean square (RMS) value of the acceleration is also monitored. The drop in this value is used as a sign of change in the natural frequency of the specimen. The impact test is carried out again with a light wooden mallet to find the new modal frequency. This procedure is repeated until the catastrophic failure. The failure of the specimen is defined as when it can no longer show amplitude at the free end. For each specimen modal frequency, fatigue cycles, and crack depth are measured. At every intermediate stage crack, depths are measured by a digital microscope with a magnification of 200x as shown in figure 6 .
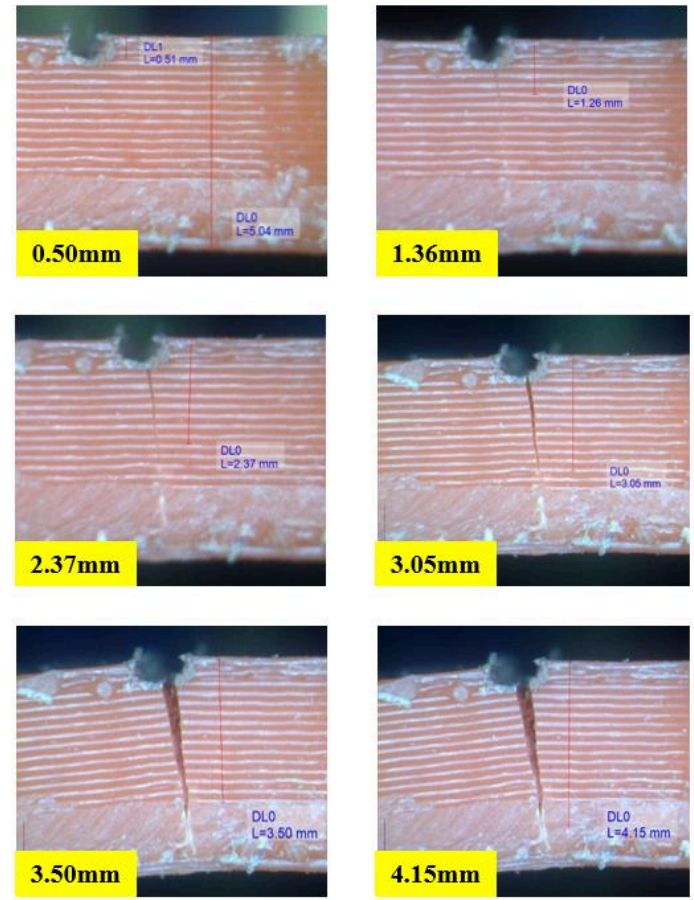
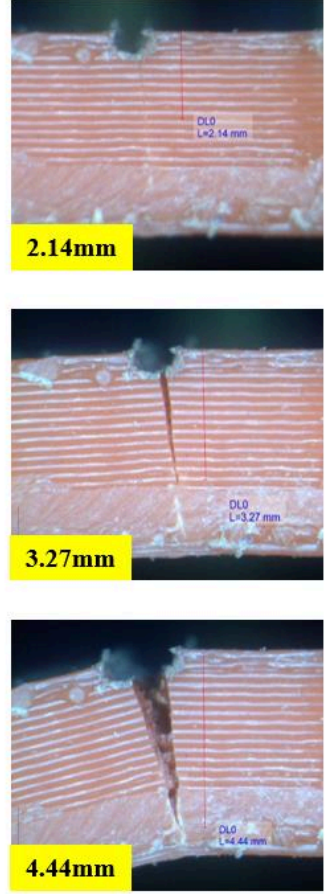

Figure 6: Crack depth measurement from the top surface of the specimen showing the evolution of crack propagation. 
Experimental and analytical data with percentage error is presented in table 2 to table 4 . For each length, analytical results are also calculated using equation (13) and compared with experimental results and curve fitting data. Experimental and analytical results are in good agreement for all configurations. The value of natural frequency at $0.5 \mathrm{~mm} \mathrm{crack}$ depth is the first fundamental frequency of the specimen. The crack will propagate under load, this will reduce the stiffness ultimately causing a decrease in the natural frequency as shown in figure 7 to figure 9 . In these figures, experimental results are plotted with a circular marker. This can also be validated via equation (13), where the corrective function i.e., $F\left(t_{c} / H\right)$ increases with the crack depth and consequently causing a decrease in the cracked beam natural frequency.

Table 2: Predicted crack depth via two approaches with percentage error, $\mathrm{L}=110 \mathrm{~mm}$

\begin{tabular}{|c|c|c|c|}
\hline Frequency & $\begin{array}{c}\text { Crack depth } \\
\text { (Experimental) }\end{array}$ & $\begin{array}{c}\text { Crack depth } \\
\text { (Analytical) }\end{array}$ & \% Error \\
\hline$[\mathbf{H z}]$ & {$[\mathbf{m m}]$} & {$[\mathbf{m m}]$} & \\
\hline 57.60 & 0.50 & 0.50 & - \\
\hline 54.10 & 1.36 & 1.49 & 9.56 \\
\hline 49.50 & 2.14 & 2.11 & 1.40 \\
\hline 44.10 & 2.37 & 2.54 & 7.17 \\
\hline 38.50 & 3.05 & 2.90 & 5.01 \\
\hline 33.00 & 3.27 & 3.19 & 2.39 \\
\hline 27.60 & 3.50 & 3.47 & 0.94 \\
\hline 22.00 & 3.85 & 3.75 & 2.57 \\
\hline 16.50 & 3.96 & 4.03 & 1.87 \\
\hline 11.00 & 4.44 & 4.34 & 2.30 \\
\hline 9.80 & 4.57 & 4.44 & 2.78 \\
\hline 7.90 & 4.67 & 4.61 & 1.31 \\
\hline 6.80 & 4.83 & 4.70 & 2.77 \\
\hline
\end{tabular}

Table 3: Predicted crack depth via two approaches with percentage error, $\mathrm{L}=130 \mathrm{~mm}$

\begin{tabular}{|c|c|c|c|}
\hline Frequency & $\begin{array}{c}\text { Crack depth } \\
\text { (Experimental) }\end{array}$ & $\begin{array}{c}\text { Crack depth } \\
\text { (Analytical) }\end{array}$ & \% Error \\
\hline 44.20 & 0.50 & 0.50 & - \\
\hline 38.50 & 1.97 & 2.16 & 9.64 \\
\hline 33.00 & 2.86 & 2.79 & 2.31 \\
\hline 27.50 & 3.00 & 3.21 & 7.18 \\
\hline 22.00 & 3.47 & 3.61 & 3.91 \\
\hline 16.50 & 3.88 & 3.98 & 2.50 \\
\hline 14.00 & 3.99 & 4.15 & 3.96 \\
\hline 11.00 & 4.28 & 4.40 & 2.90 \\
\hline 9.80 & 4.39 & 4.52 & 2.87 \\
\hline 8.60 & 4.54 & 4.63 & 1.92 \\
\hline
\end{tabular}

Table 4: Predicted crack depth via two approaches with percentage error, $\mathrm{L}=150 \mathrm{~mm}$

\begin{tabular}{|c|c|c|c|}
\hline Frequency & $\begin{array}{c}\text { Crack depth } \\
\text { (Experimental) }\end{array}$ & $\begin{array}{c}\text { Crack depth } \\
\text { (Analytical) }\end{array}$ & $\begin{array}{c}\% \\
\text { Error }\end{array}$ \\
\hline 33.40 & 0.50 & 0.50 & - \\
\hline 27.50 & 2.73 & 2.54 & 6.86 \\
\hline 22.00 & 2.99 & 3.23 & 7.92 \\
\hline 16.50 & 3.87 & 3.79 & 2.14 \\
\hline 11.00 & 4.48 & 4.33 & 3.33 \\
\hline 9.00 & 4.56 & 4.57 & 0.13 \\
\hline 8.00 & 4.62 & 4.69 & 1.63 \\
\hline 7.00 & 4.73 & 4.81 & 1.65 \\
\hline 6.00 & 4.87 & 4.93 & 1.17 \\
\hline 5.50 & 4.92 & 4.99 & 1.34 \\
\hline
\end{tabular}




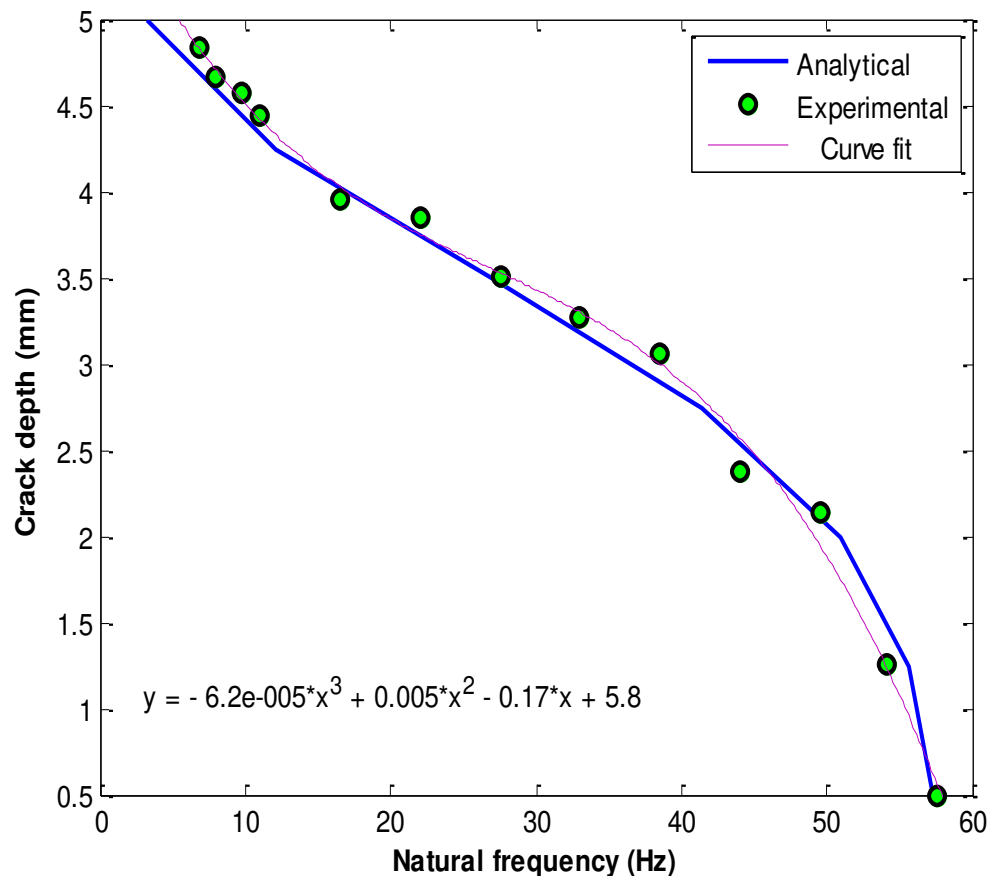

Figure 7: Variation of predicted crack depth with respect to natural frequency, $\mathrm{L}=110 \mathrm{~mm}$

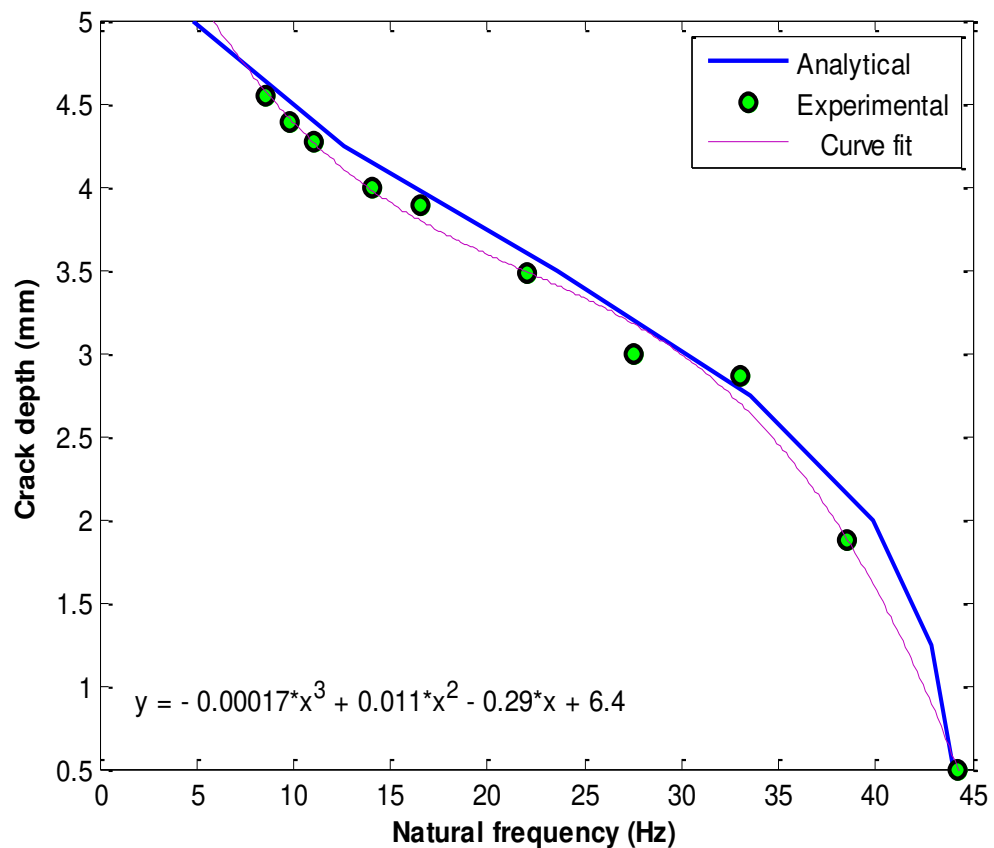

Figure 8: Variation of predicted crack depth with respect to natural frequency, $\mathrm{L}=130 \mathrm{~mm}$ 


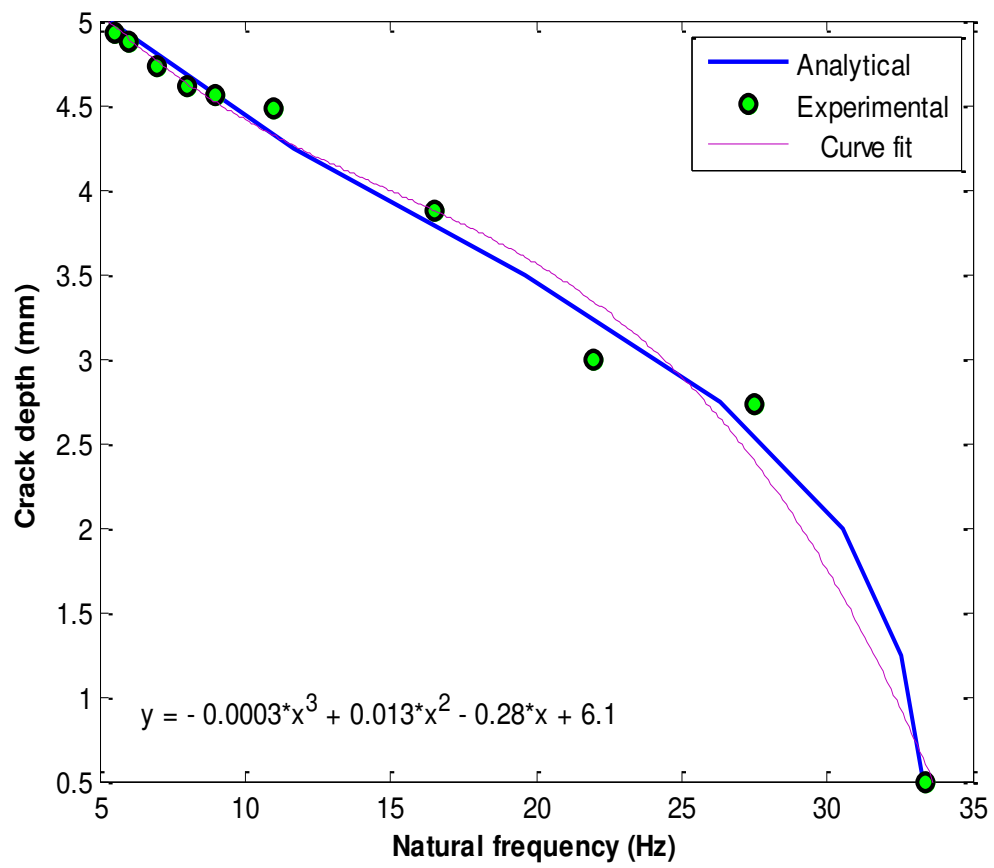

Figure 9: Variation of predicted crack depth with respect to natural frequency, $L=150 \mathrm{~mm}$

Analytical modeling can be used to get the crack propagation from initiation to failure. These visually measured crack depth values are compared with the values obtained from equation (13). Percentage error of less than $10 \%$ is obtained in all three configurations. The empirical relations obtained via cubic fit are presented in equations (15) - (17) for all three configurations of $\mathrm{L}=110 \mathrm{~mm}, \mathrm{~L}=130 \mathrm{~mm}$ and $\mathrm{L}=150 \mathrm{~mm}$ respectively. This will help in a quick and accurate estimation of crack depth based on the dynamic response for a particular length of the specimen.

$$
\begin{aligned}
& t c=-6.2 e^{-5} \omega_{n c}{ }^{3}+0.005 \omega_{n c}{ }^{2}-0.17 \omega_{n c}+5.8 \\
& t c=-17 e^{-5} \omega_{n c}{ }^{3}+0.011 \omega_{n c}{ }^{2}-0.29 \omega_{n c}+6.4 \\
& t c=-30 e^{-5} \omega_{n c}{ }^{3}+0.013 \omega_{n c}{ }^{2}-0.28 \omega_{n c}+6.1
\end{aligned}
$$

Additionally, a polynomial curve fitting was done on available data to obtain a global empirical relation which can accommodate a range of frequencies and lengths of the specimen as shown in equations (18) - (19). Crack depth is plotted as a function of frequency and length as shown in figure 10. 


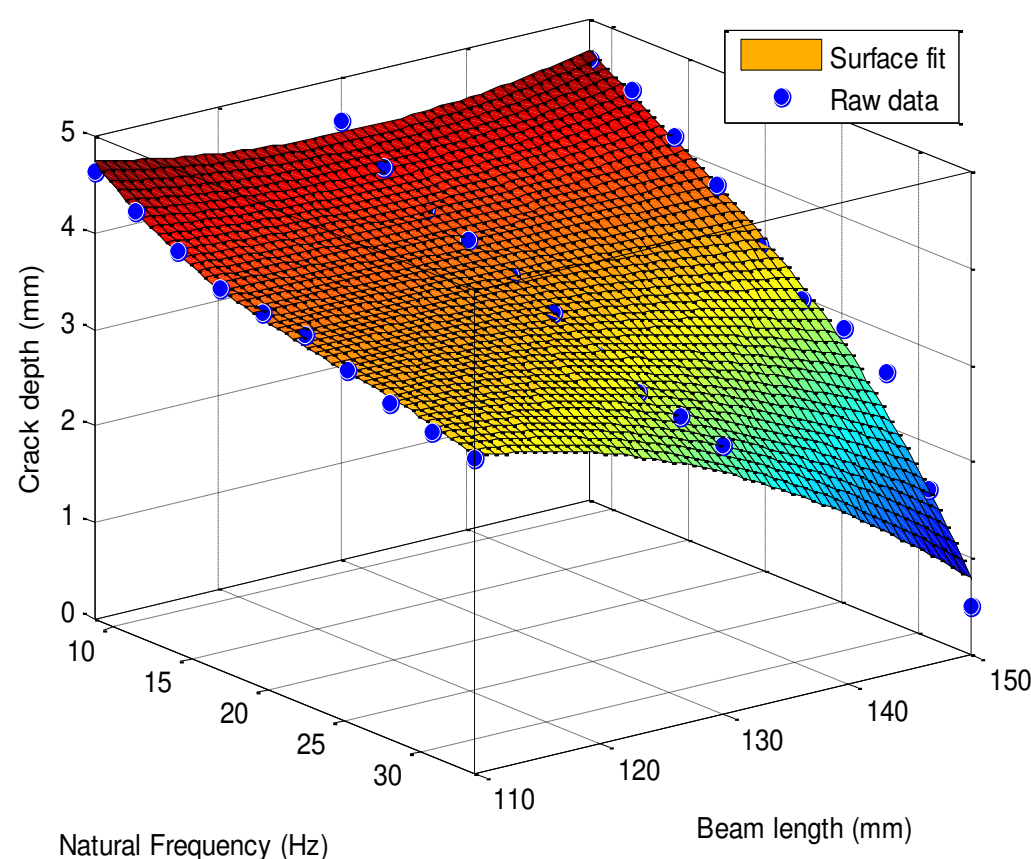

Figure 10: Comparison of experimental and surface fit data for crack depth

$$
t c=f\left(\omega_{n c}, L\right)
$$

$t c=p_{0}+p_{10} \omega_{n c}+p_{1} L+p_{20} \omega_{n c}{ }^{2}+p_{11} \omega_{n c} L+p_{2} L^{2}+p_{30} \omega_{n c}{ }^{3}+p_{21} \omega_{n c}{ }^{2} L+p_{12} \omega_{n c} L^{2}$

Where:

$\omega_{n c}=$ natural frequency

$L=$ length of the specimen

tc $=$ crack depth

$p_{0}, p_{10}, p_{1}, p_{20}, p_{11}, p_{2}, p_{30}, p_{21}, p_{12}=$ coefficient which are calculated based on the selection of natural frequency and length of the specimen.

Experimental results are plotted with the results obtained via a global empirical equation, and found in good agreement as shown in figure 11. In this plot crack depths with respect to natural frequencies are plotted for three lengths $110 \mathrm{~mm}$, $130 \mathrm{~mm}$ and $150 \mathrm{~mm}$. The discrete points (Circular, square \& diamond marker) are the experimental results for each length. The continuous plots are crack depths obtained using global correlation as shown in equation (19). This function can be applied to a fixed range of frequency, therefore, it best fits from the minimum first natural frequency $(34.5 \mathrm{~Hz})$ in the data to a fixed lowest frequency $(8.6 \mathrm{~Hz})$. These values are selected to set a fixed range of frequencies of all three datasets of each configuration. Any length between $110 \mathrm{~mm}$ to $150 \mathrm{~mm}$ can be selected for this function. It can be observed from the result that the longer specimen has faster crack propagation with respect to same frequency drop. It is also found out that below $15 \mathrm{~Hz}$ or at higher crack depths, the entire three specimens behave in a similar manner regardless of their lengths. The global empirical relation can be used to predict around $85 \%$ of available date and validation within $10 \%$ of error. 


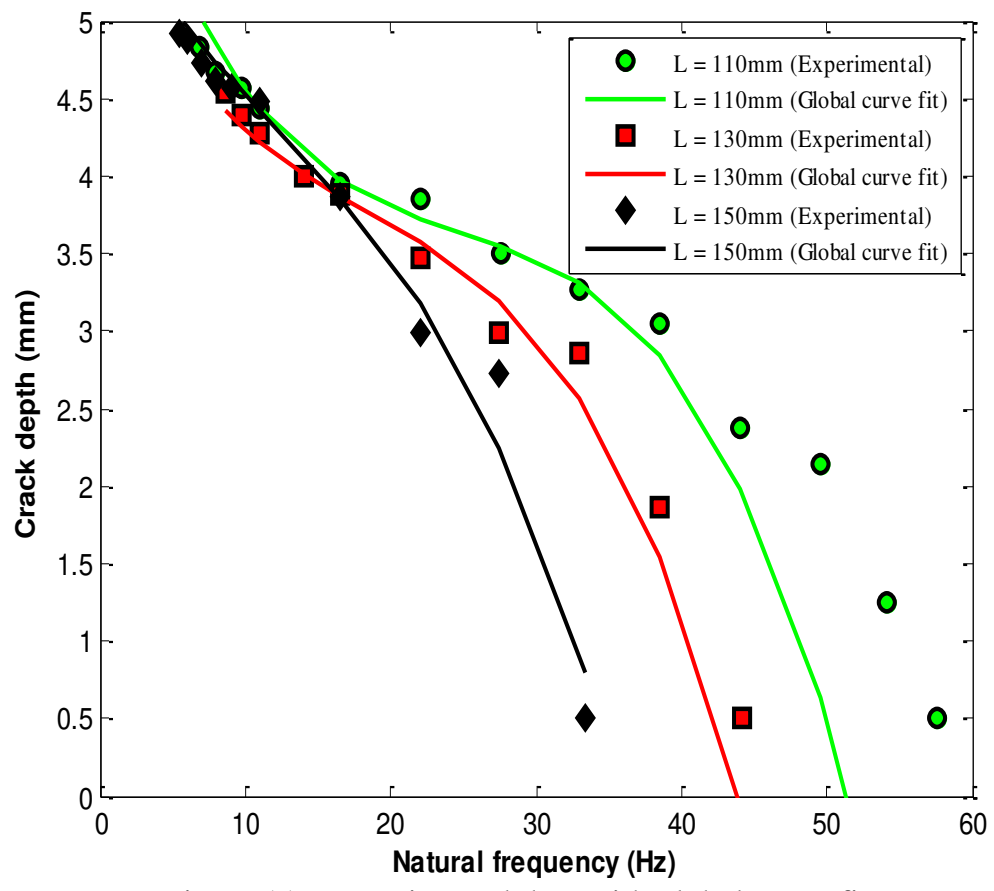

Figure 11: Experimental data with global curve fit

\subsection{Estimation of residual fatigue life}

This section provides a discussion on residual fatigue life of the specimens. In order to estimate this fatigue life two parameters fractional frequency drop $(r)$ and residual fatigue life $(\mathrm{Nr})$ are calculated based on experimental data as shown in equations (20) - (21). [47].

$$
\begin{aligned}
& r=\left[1-\frac{f}{f_{i}}\right] \\
& N r=\left[1-\frac{N}{N_{f}}\right]
\end{aligned}
$$

Where:

$f=$ fundamental frequency at any instance

$f_{i}=$ initial natural frequency

$N=$ accumulated number of cycles

$N_{f}=$ total number of cycles till failure

For each configuration of the specimen, three separate tests are performed as shown in figure 12. The results show the total number of cycles and the relevant first natural frequency drop until fracture of the specimen. Insignificant variations in the values of natural frequencies and the total number of cycles are observed for specimens of the same length. The reason for these variations is possibly due to dimensional tolerances in the manufacturing process and minor variation in boundary condition including tightening force. The results obtained from these samples can be compared with the metallic beams to investigate the respective fatigue life. The possible change in natural frequency with increasing crack depth can also be investigated. 


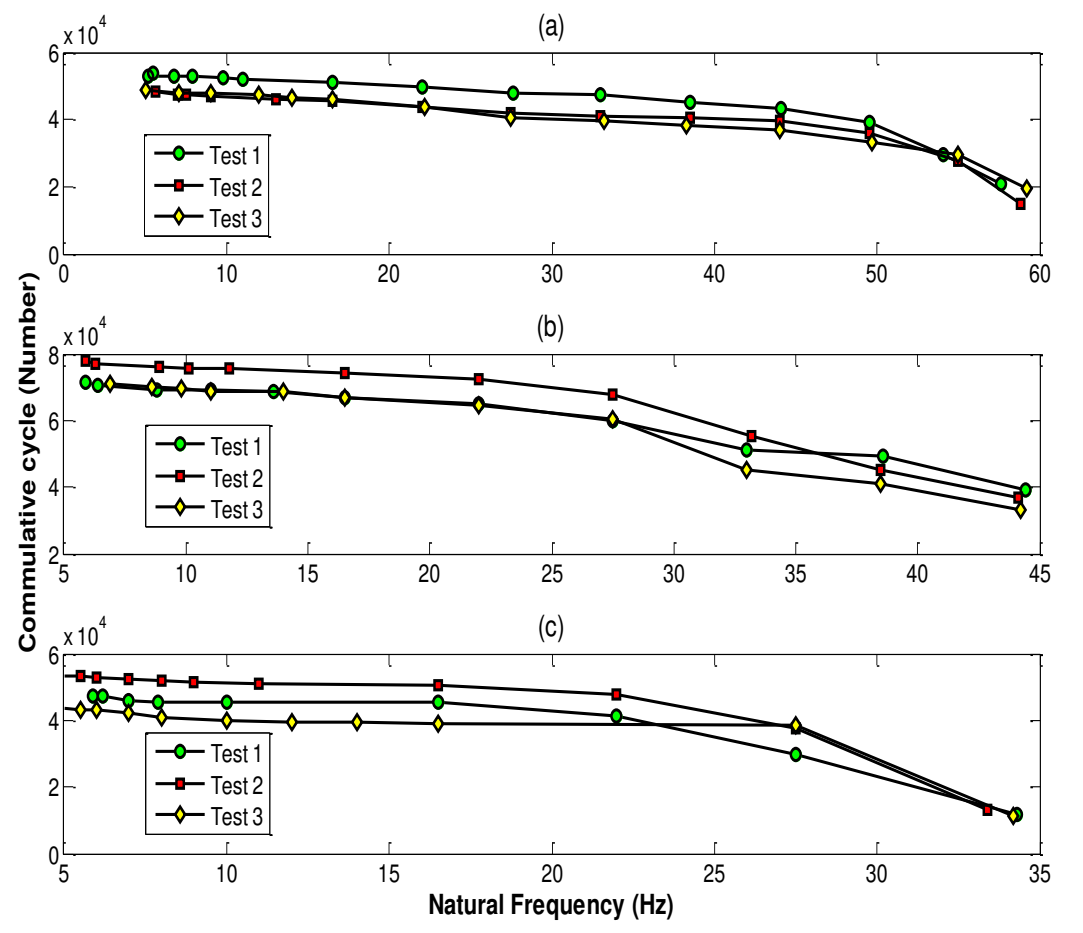

Figure 12: Experimental cumulative fatigue cycle data (a) $\mathrm{L}=110 \mathrm{~mm}$, (b) $\mathrm{L}=130 \mathrm{~mm}$, (c) $\mathrm{L}=150 \mathrm{~mm}$

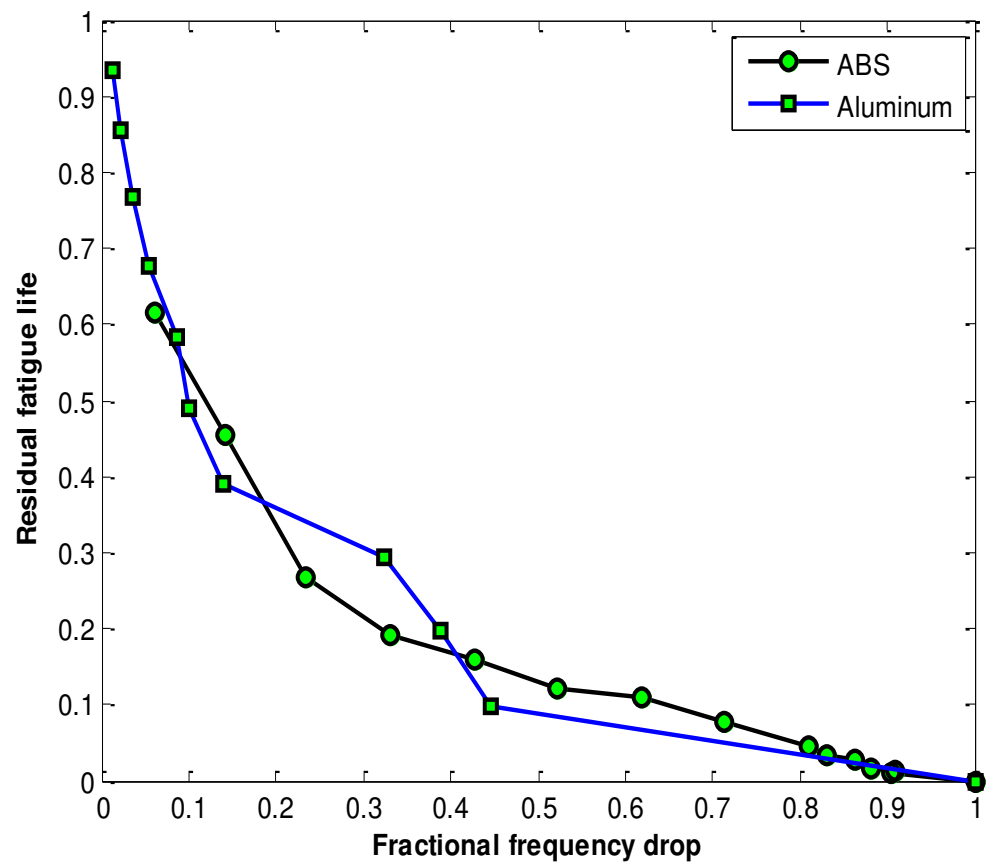

Figure 13: Residual fatigue life for a specimen having $\mathrm{L}=110 \mathrm{~mm}$ 


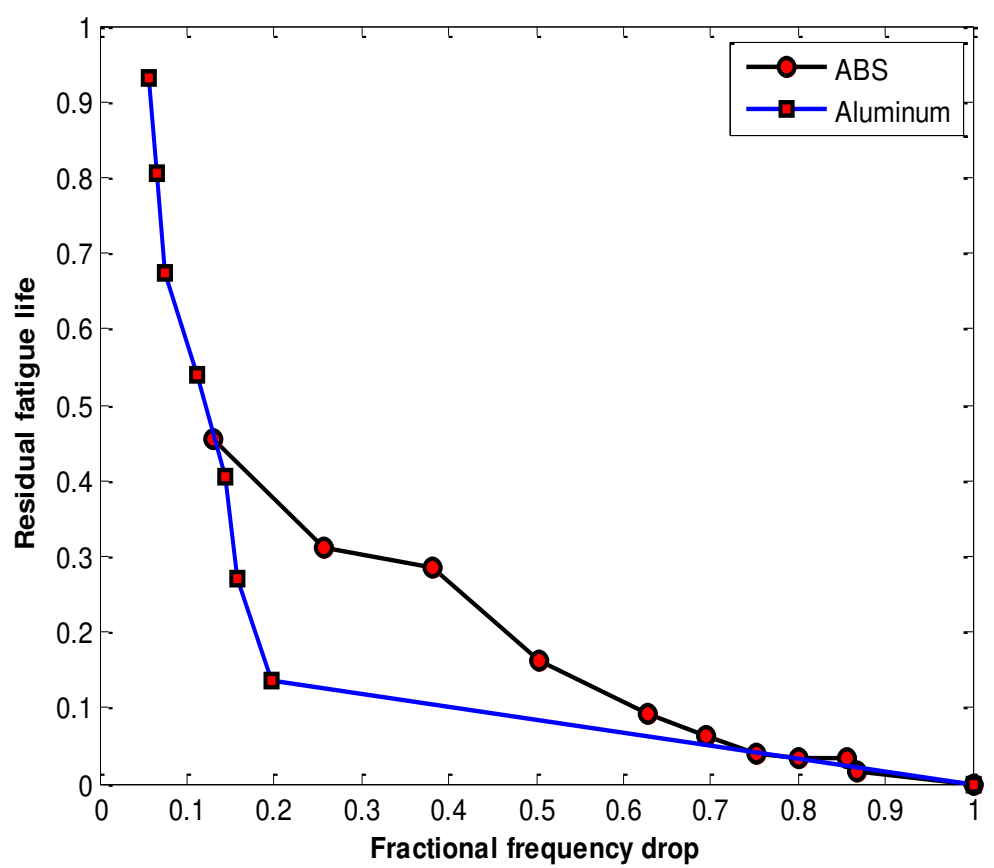

Figure 14: Residual fatigue life for a specimen having $\mathrm{L}=130 \mathrm{~mm}$

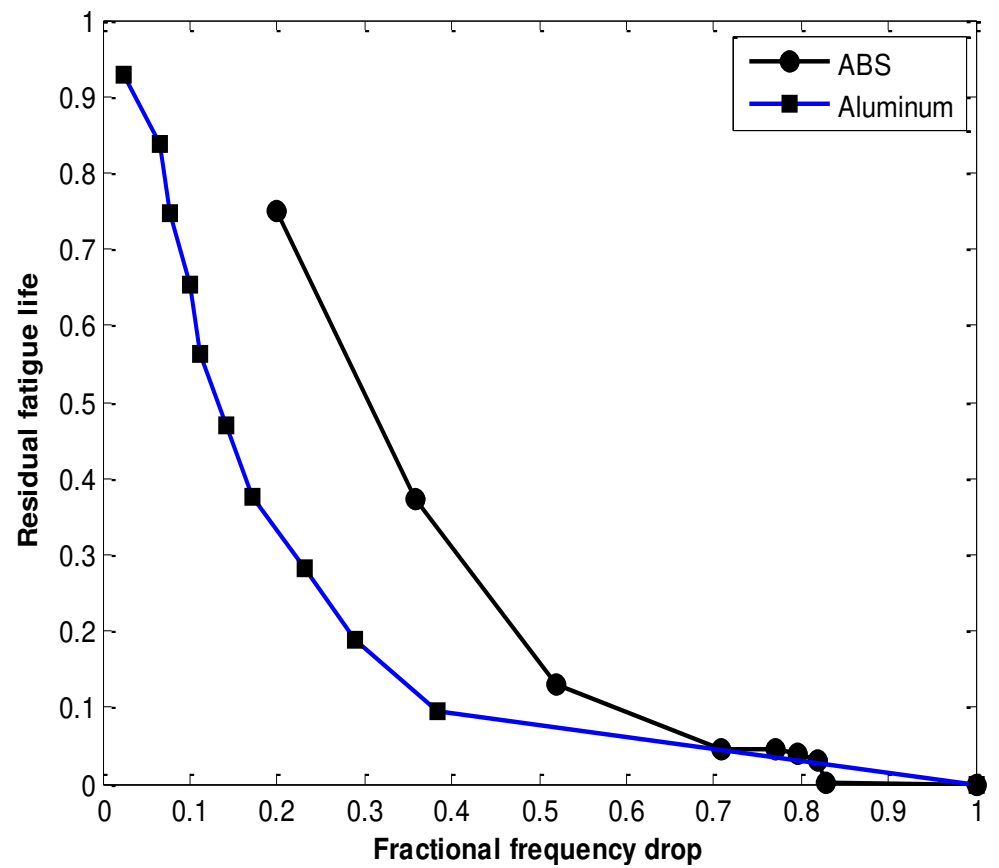

Figure 15: Residual fatigue life for a specimen having $\mathrm{L}=150 \mathrm{~mm}$

The available data for ABS material is analyzed and compared with the published results of similar metallic structure (Aluminum 1050) [47]. The results show that the maximum time is taken to achieve the first drop in natural frequency. The presence of a crack can change the material properties subsequently, causing the drop in its natural frequency till catastrophic failure. Specimens which are manufactured by FDM are found to have more residual fatigue life compared to metallic structure (Aluminum 1050) at same frequency drop under cyclic loading for all configurations as shown in figure 13 - figure 15. This shows that the residual fatigue life of a specimen can be determined by using the fractional frequency drop. Mathematically, an empirical correlation can be obtained from these trends which can be used to estimate the remaining number of cycles at any instance of operation. Currently, FDM technology is being used to manufacture different machine components. Therefore, the presented technique can be very effective in order to predict the possible crack in the component as well as its remaining fatigue life using the dynamic response. 


\section{Conclusion}

A methodology is proposed to predict the crack depth in Acrylonitrile Butadiene Styrene (ABS) beam, operating at a modal frequency by its dynamic response values. The methodology is based on in-situ operating condition to predict the depth of a propagating crack. Analytical relations are presented along with empirical correlations. The predicted results are well within $10 \%$ of error using fundamental frequency at an instant for all configurations. A global curve fit is also formulated which can be used to predict the crack depth for the same range of fundamental frequency and length. The function for experimental and surface fit data is obtained with a fix range of frequency. Therefore, this function best fits from minimum first natural frequency $(34.5 \mathrm{~Hz})$ in the data to a fixed lowest frequency $(8.6 \mathrm{~Hz})$ and for lengths between $110 \mathrm{~mm}$ to 150 $\mathrm{mm}$. This global function can be used to predict around $85 \%$ of the data for validation within $10 \%$ of error. Moreover, for investigating the residual fatigue life, it is found out that the ABS have greater residual life at same frequency drop compared to metallic (Aluminum 1050) structure. This property of ABS will lead to its efficient use as machine components under cyclic loading.

\section{References}

1. A. Bernard and A. Fischer, "New Trends in Rapid Product Development," CIRP Annals 51, no. 2 (Jan 2002): 635-652, https://doi.org/10.1016/S0007-8506(07)61704-1

2. J. Rodriguez, J. Thomas and J. E. Renaud, "Design of Fused-Deposition ABS Components for Stiffness and Strength," J of Mechanical Design 125, no. 3 (Sep 2003): 545-551, https://doi:10.1115/1.1582499

3. S. Masood, "Intelligent rapid prototyping with fused deposition modeling," Rapid Prototype J 2, no. 1 (Mar 1996): 24-33, https://doi.org/10.1108/13552549610109054

4. B. Berman, “3-D Printing: The New Industrial Revolution,” Business Horizon 55, no. 2 (Mar 2012): 155-162, https://doi.org/10.1016/j.bushor.2011.11.003

5. T. Letcher, B. Rankouhi and S. Javadpour, "Experimental Study of Mechanical Properties of Additively Manufactured ABS Plastic as a Function of Layer Parameters" (paper presentation, ASME 2015 International Mechanical Engineering Congress and Exposition, Houston, Texas, November 13-19, 2015).

6. H. Wang, H. Zhou, Z. Huang, Y. Zhang, H. Qiao and Z. Yu, "Experimental Investigation and Modeling of the Mechanical Behavior of PC/ABS during Monotonic and Cyclic Loading," Polymer Testing 50 (April 2016): 216223, https://doi.org/10.1016/j.polymertesting.2015.12.010

7. Ö. Keleş, C. Wayne Blevins and K. Bowman, "Effect of Build Orientation on the Mechanical Reliability of 3D Printed ABS,” J Rapid Prototype 23, no. 2 (Mar 2016): 320-328, https://doi.org/10.1108/RPJ-09-2015-0122

8. V. Vashishtha, R. Makade and N. Mehla, "Advancement of Rapid Prototyping in Aerospace Industry - A Review," Int J Engineering Science \& Technology 3, no. 3 (Mar 2011): 2486-2493

9. W. D. Macy, "Rapid/Affordable Composite Tooling Strategies Utilizing Fused Deposition Modeling," Proc. Soc. Advance Material Process Engineering 47 (Jul 2011): 1-14

10. O. A. Mohamed, S. H. Masood and J. L. Bhowmik, "Experimental Investigation of Time-Dependent Mechanical Properties of PC-ABS Prototypes Processed by FDM Additive Manufacturing Process," Material Letters 193 (April 2017): 58-62, https://doi.org/10.1016/j.matlet.2017.01.104

11. A. Garg, A. Bhattacharya and A. Batish, "Failure Investigation of Fused Deposition Modeling Parts Fabricated At Different Raster Angles Under Tensile and Flexural Loading," J of Engineering Manufacture 231, no. 11 (Sep 2017): 2031-2039, https://doi.org/10.1177/0954405415617447

12. J. Rodriguez, J. Thomas and J. E. Renaud, "Mechanical Behavior of Acrylonitrile Butadiene Styrene (ABS) Fused Deposition Materials. Experimental Investigation," Rapid Prototype J 7, no. 3 (Aug 2001): 148-158, https://doi.org/10.1108/13552540110395547

13. A. Arivazhagan and S. Masood, "Dynamic Mechanical Properties of ABS Material Processed by Fused Deposition Modeling," International J Engineering Research and Application 2, no. 3 (Jan 2012), http://hdl.handle.net/1959.3/315549

14. J. Lee and A. Huang, "Fatigue Analysis of FDM Materials," Rapid Prototype J 19, no. 4 (Jun 2013): 291-299, https://doi.org/10.1108/13552541311323290

15. H. Zhang, L. Cai, M. Golub, Y. Zhang, X. Yang, K. Schlarman and J. Zhang, "Tensile, Creep, and Fatigue Behaviors of 3D-Printed Acrylonitrile Butadiene Styrene," J of Material Engineering and Performance 27, no. 1 (Jan 2018): 57-62, http://dx.doi.org/10.1007/s11665-017-2961-7

16. A. Imeri, I. Fidan, M. Allen, D. Wilson and S. Canfield "Fatigue Analysis of the Fiber Reinforced Additively Manufactured Objects," Int J of Advanced Manufacturing Technology 98, no. 9 (July 2018), https://doi.org/10.1007/s00170-018-2398-7

17. J. A. Suresh, S. K. Gurunathan, P. Ramu and J. Rengaswamy, "Fatigue Life Characterization of Additively 
Manufactured Acrylic like Poly-Jet Printed Parts,” Advances in Structure Integrity, (Dec 2017): 623-632, https://doi.org/10.1007/978-981-10-7197-3_52

18. M. F. Afrose, S. H. Masood, P. Iovenitti, M. Nikzad and I. Sbarski, "Effects of Part Build Orientations on Fatigue Behaviour of FDM-Processed PLA Material," Progress in Additive Manufacturing 1, no. 1-2 (June 2016): 2128, https://doi.org/10.1007/s40964-015-0002-3

19. C. W. Ziemian, R. D. Ziemian and K. V. Haile, "Characterization of Stiffness Degradation Caused by Fatigue Damage of Additive Manufactured Parts," Material and Design 109 (Nov 2016): 209-218, https://doi.org/10.1016/j.matdes.2016.07.080

20. Q. Fang, T. Wang and H. Li, “Tail' Phenomenon and Fatigue Crack Propagation of PC/ABS Alloy,” Polymer Degradation and Stability 93, no. 1 (Jan 2018): 281-290,https://doi.org/10.1016/j.polymdegradstab.2007.09.002

21. M. Fischer and V. Schöppner, "Fatigue Behavior of FDM Parts Manufactured with Ultem 9085," J of Minerals, Metals and Material Society 69, no. 3 (Mar 2017): 563-568, https://doi.org/10.1007/s11837-016-2197-2

22. A. S. J. Swamidas and Y. Chen, "Monitoring Crack Growth Through Change of Modal Parameters," J of Sound and Vibration 186, no. 2 (Sep 1995): 325-343, https://doi.org/10.1006/jsvi.1995.0452

23. D. P. Patil and S. K. Maiti, "Experimental Verification of a Method Of Detection of Multiple Cracks in Beams Based on Frequency Measurements," J of Sound and Vibration 281, no. 1 (Mar 2005): 439-451, https://doi.org/10.1016/j.jsv.2004.03.035

24. Rao S.S, Mechanical Vibrations $2^{\text {nd }}$ Ed. (USA: Addison-Wesley publishing company, 1990)

25. M. A. Khan, S. Z Khan, W. Sohail, H. Khan, H, M. Sohaib and S. Nisar, "Mechanical Fatigue in Aluminum at Elevated Temperature and Remaining Life Prediction Based on Natural Frequency Evolution," Fatigue Fracture Engineering Material Structure 38 (2015): 897-903, https://doi.org/10.1111/ffe.12287

26. L. H. Chen, Y. Sun and W. Zhang, "Study of Vibration Characteristics of Cantilever Rectangular Plate with Side Crack," Applied Mechanics and Materials 226-228 (Nov 2012): 113-118, https://doi.org/10.4028/www.scientific.net/AMM.226-228.113

27. M. Sangid, H. Maier and H. Sehitoglu, "The Role of Grain Boundaries on Fatigue Crack Initiation - An Energy Approach,” Int J of Plasticity 27, no. 5 (May 2011): 801-821, https://doi.org/10.1016/j.ijplas.2010.09.009

28. S. Orhan, "Analysis of Free and Forced Vibration of a Cracked Cantilever Beam," NDT E International 40, no. 6 (Sep 2007): 443-450, https://doi.org/10.1016/j.ndteint.2007.01.010

29. E. Çam, S. Orhan and M. Lüy, "An Analysis of Cracked Beam Structure Using Impact Echo Method," NDT E International 38, no. 5 (July 2005): 368-373, https://doi.org/10.1016/j.ndteint.2004.10.009

30. T. J. George, J. Seidt, M. H. Herman Shen, T. Nicholas and C. J. Cross, "Development of A Novel VibrationBased Fatigue Testing Methodology," Int. J Fatigue 26, no. 5 (May 2004): 477-486, https://doi.org/10.1016/j.ijfatigue.2003.10.012

31. P. G. Nikolakopoulos, D. E. Katsareas and C. A. Papadopoulos, "Crack Identification in Frame Structures," Computer \& Structure 64, no. 1 (July 1997): 389-406, https://doi.org/10.1016/S0045-7949(96)00120-4

32. A. J. Dentsoras and E. P. Kouvaritakis, "Effects of Vibration Frequency on Fatigue Crack Propagation of a Polymer at Resonance," Engineering Fracture Mechanics 50, no. 4 (Mar 1995): 467-473, https://doi.org/10.1016/0013-7944(94)00226-8

33. A. Garg and A. Bhattacharya, "An Insight to The Failure of FDM Parts Under Tensile Loading: Finite Element Analysis and Experimental Study," Int J Mechanical Science 120 (Jan 2017): 225-236, https://doi.org/10.1016/j.ijmecsci.2016.11.032

34. R. Behera, D. A. Pandey and D. Parhi, "Numerical and Experimental Verification of a Method for Prognosis of Inclined Edge Crack in Cantilever Beam based on Synthesis of Mode Shapes," Procedia Technology 14 (Dec 2014): 67-74, https://doi.org/10.1016/j.protcy.2014.08.010

35. V. Khalkar and S. Ramachandran, "Comparative Vibration Study of EN 8 And EN 47 Cracked Cantilever Beam," J of Vibroengineering 19, no 1 (Feb 2017): 246-259, https://doi.org/10.21595/jve.2016.17394

36. V. Khalkar and S. Ramachandran, "Free Vibration Study of V-Shape and Rectangular Shape Double-Sided Cracks in a Cantilever Beam," J of Vibroengineering 19, no. 2 (Mar 2017): 1026-1038, https://doi.org/10.21595/jve.2016.17653

37. V. Khalkar and S. Ramachandran, "The Effect of Crack Geometry on Stiffness of Spring Steel Cantilever Beam," J of Low Frequency Noise Vibration and Active Control (2018), DOI: 10.1177/1461348418765959.

38. V. Khalkar and S. Ramachandran, "Study of Free Undamped and Damped Vibrations of a Cracked Cantilever Beam," J of Engineering Science and Technology 13, no. 2 (Feb 2018): 449-462

39. G. Owolabi, A. Peterson, E. Habtour, J. Riddick, M. Coatney, A. Olasumboye and D. Bolling, "Dynamic Response of Acrylonitrile Butadiene Styrene Under Impact Loading," Int J of Mechanical and Materials Engineering 11, no. 3 (2016), https://doi.org/10.1186/s40712-016-0056-0

40. A. Peterson, E. Habtour, J. Riddick, M. Coatney, D. Bolling and G. Owolabi, "Dynamic Evaluation of Acrylonitrile Butadiene Styrene Subjected to High-Strain Rate Compressive Loads," U.S. Army Research Laboratory, (2014), https://apps.dtic.mil/dtic/tr/fulltext/u2/a612838.pdf

41. P. Jindal, J. Jyoti and N. Kumar, "Mechanical Characterization Of ABS/MWCNT Composites Under Static and 
Dynamic Loading Conditions,” J of Mechanical Engineering and Sciences 10, no. 3 (Dec 2016): 2288-2299, https://doi.org/10.15282/jmes.10.3.2016.7.0213

42. S. H. Masood. "Introduction to Advances in Additive Manufacturing and Tooling". Comprehensive Materials Processing 10 (2014): 1-2, http://dx.doi.org/10.1016/B978-0-08-096532-1.01016-5

43. S.Z. Khan, S. Masood and R. Cottam, "Mechanical Properties of a Novel Ply-Metal Manufactured By LaserAssisted Direct Metal Deposition," The Int J of Advanced Manufacturing Technology 91, no. 5-8 (Nov 2016): 1839-1849, https://doi.org/10.1007/s00170-016-9851-2

44. W. Ostachowicz and M. Krawczuk "Analysis of the Effect of Cracks on the Natural Frequencies of a Cantilever Beam", J of Sound and Vibration 150, no. 2 (Oct 1991); 191-201, https://doi.org/10.1016/0022-460X(91)90615Q

45. A. Majid, "Diagnosis of Type Location and Size of Cracks by Using Generalized Differential Quadrature and Rayleigh Quotient Methods," J of Theoretical and Applied Mechanics 43, no. 1 (Mar 2013): 61-70, https://doi.org/10.2478/jtam-2013-0006

46. Y. Lee, Fatigue Testing and Analysis: Theory and Practice, (Elsevier Butterworth-Heinemann. UK, 2005).

47. M. A. Khan, K. A. Khan, S. Z. Khan, S. Nisar and A. Starr, "Fracture Life Estimation of Al-1050 Thin Beams Using Empirical Data and A Numerical Approach," Insight - Non-Destructive Testing and Condition Monitoring 60, no. 7 (2018): 363-368, https://doi.org/10.1784/insi.2018.60.7.363 
2019-04-10

Prediction of crack depth and fatigue life of an acrylonitrile butadiene styrene cantilever beam using dynamic response

\section{Zai, Behzad Ahmed}

ASTM International

Zai BA, Khan MA, Khan SZ, et al., (2020) Prediction of crack depth and fatigue life of an acrylonitrile butadiene styrene cantilever beam using dynamic response. Journal of Testing and Evaluation, Volume 48, Issue 2, March 2020, pp. 1520-1536

https://doi.org/10.1520/JTE20180674

Downloaded from Cranfield Library Services E-Repository 